\title{
A Retrospective Study of Long Acting Risperidone Use to Support Treatment Adherence in Youth with Conduct Disorder
}

\author{
Sevcan Karakoç Demirkaya, Hatice Aksu, Börte Gürbüz Özgür \\ Department of Child and Adolescent Psychiatry, Adnan Menderes University Faculty of Medicine, Aydın, Turkey
}

\begin{abstract}
Objective: Risperidone has been widely used to control aggression and conduct disorder (CD) in youth; however, treatment compliance is a major problem in CD. Our aim is to evaluate the effectiveness and tolerability of long-acting risperidone (LAR) in treating nonadherent cases.

Methods: The medical records of children and adolescents who had CD and were nonadherent to conventional drugs and psychosocial interventions (and therefore taking LAR) were reviewed. Informed consent on offlabel use of LAR was obtained from the parents. Clinical Global Impression (CGI) Severity (CGI-S) and CGI-Improvement scales were used and baseline and end points were compared.

Results: The study comprised 14 children and adolescents (5 girls, 9 boys). All had comorbid disorders: substance use disorder $(n=8)$, attention deficit hyperactivity disorder $(n=6)$, and major depression $(n=2)$. Mean duration of LAR use was 3.1 months (1.5-8 months). We observed significant improvements in the baseline and endpoint CGI-S scores for CD in all but one patient $(Z=-3.198 ; p<0.001)$. Only mild adverse effects were observed: weight gain $(n=2)$, sedation $(n=1)$, leg cramps $(n=1)$, and increased appetite with no weight gain $(n=1)$.

Conclusion: LAR is effective and tolerable for patients with CD who can't be medicated with oral preparations due to nonadherence to treatment. Even short-term LAR use is effective to get compliance. As CD predicts numerous problems in adulthood, appropriate treatment is crucial. To our knowledge, this is the first study on LAR use in youth with CD. The use of LAR deserves careful consideration and further controlled studies are needed to confirm our findings.
\end{abstract}

KEY WORDS: Antipsychotic agents; Risperidone; Conduct disorder.

\section{INTRODUCTION}

Conduct disorder $(\mathrm{CD})$ is a repetitive and persistent pattern of behavior characterized by aggression towards people and animals, harming the property of others, and serious violations of age-appropriate rules. ${ }^{1)} \mathrm{CD}$ is a disorder that threatens both the child and those in their life. CD is one of the most common child mental health problems, with prevalence rates of $2.7 \%$ for 3 -months prevalence and $3.8 \%$ for lifetime prevalance. ${ }^{2,3)}$ It constitutes $30 \%$ to $50 \%$ of all clinical referrals and is two to three times more prevalent in males than in females. ${ }^{4-6)}$

Early diagnosis and intervention is crucial, because CD is associated with a variety of negative consequences such

\footnotetext{
Received: July 25, 2016 / Revised: September 30, 2016

Accepted: October 3, 2016

Address for correspondence: Sevcan Karakoç Demirkaya, MD Department of Child and Adolescent Psychiatry, Adnan Menderes University Faculty of Medicine, Merkez Kampus, Aydın 09010, Turkey Tel: +90-256-214-5400, Fax: +90-256-214-6495

E-mail: Sevcan.karakoc@adu.edu.tr
}

as low academic achievement, increased social problems, and poor peer relations, which lead to comorbid psychiatric disorders, substance use disorders (SUDs), adverse relationship problems (e.g., adolescent pregnancies or sexually transmitted diseases), as well as criminal problems and antisocial behaviors. ${ }^{7-9)}$ Considering all these risk factors, $\mathrm{CD}$ is one of the most important public health problems and deserves effective treatment as early as possible. ${ }^{10)}$

Treatment options for CD are family therapy, behavioral modification, and pharmacotherapy, often in combination. ${ }^{3)}$ Parent management training (PMT) is considered the most effective psychosocial intervention for $\mathrm{CD}$ and is widely used. However, the efficacy of PMT decreases in dysfunctional families, older children, with comorbid internalizing problems, and when the PMT program has not been completed. ${ }^{3,11,12)}$ Either the presence of aggression or increased disease severity indicate the need for pharmacotherapy in conjunction with psychosocial interventions. ${ }^{4}$

There has been no officially approved drug just for $C D$ itself; however, purpose of using a drug is to control ag-

(c) This is an Open-Access article distributed under the terms of the Creative Commons Attribution Non-Commercial License (http://creativecommons.org/licenses/by-nc/4.0) which permits unrestricted non-commercial use, distribution, and reproduction in any medium, provided the original work is properly cited. 
gressiveness and indirectly the $\mathrm{CD} .^{13)} \mathrm{In}$ a recent review, Gurnani et $a l .{ }^{14)}$ reported that several antipsychotics can be effective for treatment of aggression in attention deficit hyperactivity disorder (ADHD) and CD although they are not approved for this indication. ${ }^{14)}$ The antipsychotics, mostly atypical, have been studied for controlling especially severe aggression in children and adolescents so far. An open trial with aripiprazole use for $\mathrm{CD}$ has showed that aripiprazole is effective but with side effects including nause and sedation. ${ }^{15)} \mathrm{A}$ retrospective study by Masi et $a l .{ }^{16)}$ has reported that olanzapine use (5-20 mg/day) improves the symptoms of $\mathrm{CD}$ in adolescents with an adverse effect of weight gain. A placebo controlled study with a small sample size for quetiapine use (200-600 $\mathrm{mg} /$ day) in CD has suggested that quetiapine may be effective and tolerable in adolescents. ${ }^{17)}$

Among all antipsychotics, risperidone is best studied for disruptive behaviors. Risperidone is an atypical antipsychotic (AA) and the most prescribed AA drug in youth. ${ }^{18)}$ It has been shown to be an effective agent in children and adolescents with $\mathrm{CD}^{6,{ }^{6,-21)}}$ Previous studies suggest that risperidone must be an adjunctive drug in the treatment of comorbid CD and ADHD, or for patients who experience behavioral problems in addition to intellectual disabilities. ${ }^{13,20,22)}$ Recent data obtained from the Treatment of Severe Childhood Aggression (TOSCA) Study also emphasizes that risperidone improves disruptive behaviors and parent rated aggression when added to optimized stimulants and parent trainings. ${ }^{23)}$ However, same TOSCA study's 12-month follow up outcome has been recently published. Severely aggressive children with ADHD receiving additional risperidone have ended up without any significant differences in behavioral outcomes than the only stimulant received group. ${ }^{24)}$

In fact, risperidone is approved by the U.S. Food and Drug Administration (FDA) for the treatment of schizophrenia in adolescents aged 13 to 17 years and for the short-term treatment of manic or mixed episodes of bipolar I disorder in children and adolescents aged 10 to 17 years, and it is used for disruptive behaviors and irritability in children with autistic disorder who are aged five years or older. ${ }^{25)}$ Whereas in Europe it has also been approved for the treatment of persistent aggression in children with CD who have intellectual disabilities. ${ }^{26)}$ Despite its limited FDA indications, risperidone is the most commonly used AA for other psychiatric conditions in youth, especially for disruptive behaviors, aggression, and CD. ${ }^{3,23)}$ Pringsheim et $a l .{ }^{27)}$ conducted a meta-analysis and showed that there is no evidence that antipsychotics other than risperidone and mood stabilizers support the treatment of disruptive behaviors.

Treatment noncompliance and nonadherence in chronically ill pediatric age patients are major problems for clinicians and parents. Treatment nonadherence is frequent, with rates that vary from $20 \%$ to $70 \%$, depending on different factors such as age of the patient, diagnosis, and the health care system. ${ }^{28,29)}$ Aggression is the major predictor of treatment nonadherence and it has a negative impact on prognosis. The high prevalence of CD and its adverse consequences, the disease's stability over time, and its increased risk for antisocial behavior and criminality cause mental health providers to screen and intervene in $\mathrm{CD}$ as early as possible. ${ }^{6}$ Therefore, providing effective and tolerable medications for aggressive behaviors in youth is very important. ${ }^{27)}$ However, low treatment adherence is hard to manage in adolescents, because they mostly refuse to take oral drugs and to obey behavioral therapy programs. ${ }^{30,31)} \mathrm{In}$ some severe $\mathrm{CD}$ forms, treatment noncompliance causes serious problems, including: family crisis, self-mutilation, substance use, school problems, and even economic load to the health care system. ${ }^{29,31)}$ To decrease noncompliance and the impacts of poor family supervision, new pharmaceutical agents have been tried. ${ }^{32-37)}$

Long-acting risperidone (LAR) is a depot formulation whose efficacy has been studied in pediatric patients for bipolar disorder and schizophrenia. Studies of LAR use in pediatric age group have been restricted to patients diagnosed with bipolar disorder and psychotic disorders; to date, only case reports and open-label small sample studies have been reported. ${ }^{34,36-38)}$ Boarati et al. ${ }^{36)}$ found that LAR can be useful for the treatment of children and adolescents with bipolar disorder who are nonresponsive or nonadherent to conventional medications. Ruan et al. ${ }^{38)}$ conducted an open label LAR study in youth diagnosed with schizophrenia and showed that LAR is effective and safe. In a recent review, Chou et al. ${ }^{39)}$ reported that long acting injectable antipsyhotics, especially second generation antipsychotics with fewer side effects are effective treatment options in bipolar disorder. Furthermore, there are some case reports in pediatric age group with use of LAR for support treatment adherence. One case is presented by Tutkunkardaş and $\mathrm{Abali}^{35)}$ in which LAR was administered to support treatment adherence in a 16-yearold boy with ADHD and CD. The other case report is a 10 -year old boy with diagnosis of anorexia nervosa who refuses meals and as well as oral medications. ${ }^{40)}$ Both cases were treated with LAR successfully.

Treatment adherence for oral medications can be in- 
creased by switching the drug to a depot form. ${ }^{32,40)}$ AAs are considered to have fewer extrapyramidal system (EPS) side effects, and the depot form of risperidone is the most commonly used AA with a depot formulation, however data on LAR use in CD is highly limited. ${ }^{26,35,41)}$ Therefore, we aimed to evaluate the effectiveness and tolerability of LAR to support treatment adherence in children and adolescents with CD.

\section{METHODS}

\section{Participants}

We reviewed the medical records of 14 consecutive children and adolescents who were treated with LAR injection from March 2011 to March 2015 at the Department of Child and Adolescent Psychiatry, Outpatient Unit of Adnan Menderes University Research and Training Hospital. All subjects who met the following criteria were enrolled in the study:

1) Met the diagnostic criteria of $C D$, according to the Diagnostic and Statistical Manual of Mental Disorders, forth edition (DSM-IV) and/or DSM-5

2) With a Clinical Global Impressions-severity score (CGI-S) $\geq 4$ (moderately ill or more severe)

3) Did not have a diagnosis of bipolar, psychotic disorder, mental retardation, pervasive developmental disorder, or any chronic physical disorders

4) Absence of hematological or biochemical laboratory abnormalities

5) Nonadherent to conventional medications (i.e., refusal to take oral medications)

6) Nonadherent to or ineligible for psychosocial interventions (i.e., PMT) and complementary behavioral therapy

\section{Diagnosis}

In our clinic, all diagnostic evaluations are conducted by interview using the Schedule for Affective Disorders and Schizophrenia for School Age Children-Present and Lifetime Version (K-SADS-PL), which is a semi-structured interview that utilizes DSM-IV criteria. Its adaptation has been shown to be valid and reliable. ${ }^{42,43)}$ Two independent, experienced child psychiatrists (S.K.D. and H.A) had already been following up with the patients. A blinded clinician (B.G.O) retrospectively evaluated the data on file for each subject. Diagnoses were assessed and reviewed according to the DSM-IV text revision (DSMIV-TR) ${ }^{44)}$ for patients who were admitted before the date of the Turkish publication of the DSM- $5^{1)}$; in fact, the criteria for CD are the same for both versions of the DSM.

\section{Measures}

A sociodemographic data form in medical files which was filled by the clinicians routinely in our outpatient unit, was composed of the following information: Gender, age, socioeconomic status, full list of physical and mental health diagnoses, and parent current marital status and data on parental history of nicotine/alcohol/other substance use and medical/pharmacological history of the youth. All subjects had been evaluated for intelligence quotient (IQ) with Wechsler Intelligence Scale for Children-Revised by a trained psychologist.

The CGI-S and CGI-Improvement (CGI-I) scales were filled at baseline, every month, and at the endpoint. CGI-S subscale evaluates the degree of the severity of mental illness and uses a seven-point scale ( $1=$ normal, $7=$ extremely ill). The CGI-I subscale measures and uses a seven-point scale (1=very much improved, $4=$ no change, $7=$ very much worse). ${ }^{45)}$ These CGI scales were used only for the symptoms of CD, instead of other comorbid conditions if present. The evaluator was blind to the patients previous CGI scores and did not involve in following up of the patients.

\section{Procedure}

Before the administration of LAR, all parents were informed about their child's diagnosis, as well as possible outcomes and side effects of psychopharmacological treatment. As the patients had become dangerous to themselves and their surroundings, all children and their parents approved the off-label use of LAR. Because they were nonadherent to their initial oral medications; some took drugs irregularly, some did not take at all. So, we discontinued other previously prescribed medications. Initial doses of LAR $25 \mathrm{mg} /$ two weeks injections were started. The gluteal region was the preferred injection area. Weekly visits were planned at the beginning but were not achieved. In fact, due to the oppositional nature of CD and poor supervision by their parents, the participants frequently did not attend these planned appointments. Thus, the benefits and side effects of LAR treatment were discussed with the parents on weekly phone calls. Children were brought to the outpatient clinic on injection days, every two weeks.

Oral risperidone (1-2 $\mathrm{mg}$ /day) was also added to their treatment regimen at first, as the LAR protocol recommends to use oral forms of risperidone for nearly three weeks until patients' experience a steady state of LAR. ${ }^{46)}$ Since the reason for depot formulation use was the rejection of oral drugs, the participants also refused to take oral medications during follow-up. That's why the pa- 
tients took only $25 \mathrm{mg}$ LAR with no other concomitant drugs during the treatment. The dose of the LAR was always $25 \mathrm{mg} /$ two weeks, because of our national drug legislations state that outpatient referrals under 18 years old should not be prescribed any formulation of LAR except 25 $\mathrm{mg}$. At follow-up visits side effects were noted based upon patient and parent statements. Possible reasons for the reported side effects were also checked. In addition, clinicians physically examined the presence of any EPS signs.

Injections were planned to be stopped when the patient agreed to take his/her oral medications, in other terms showing improvements in CD symptoms which was considered as endpoint of the treatment. Therefore no specific treatment duration was settled in the beginning.

This study was conducted in accordance with Declaration of Helsinki for human subjects and the retrospective review has been approved by the Adnan Menderes University Local Ethics Committee (file 53043469/050.04-60).

\section{Statistical Analysis}

Statistical analyses were performed with the Statistical Package for Social Sciences (SPSS 2011) for Windows version 17.0 (SPSS Inc., Chicago, IL, USA). Compliance with the normal distribution was assessed by KolmogorovSmirnov test. Descriptive statistics were shown as number (n), ratio (\%), or mean \pm standard deviation. A Wilcoxon signed-rank nonparametric test was used to compare baseline and end-point CGI-S scores. A $p$ value less than 0.05 was taken to be statistically significant.

\section{RESULTS}

\section{Sociodemographic Characteristics}

A cohort of 14 children and adolescent subjects ( 5 girls, 9 boys) with a mean age of $13.9 \pm 2.9$ years (range, 6-17 years) was enrolled in this study. The prepubertal/postpubertal subjects' ratio was $1 / 13$. In other words, almost $93 \%$ of the participants are adolescents. The mean parents' age was $40.9 \pm 7.3$ years (range, 28-51 years), and $48.1 \pm 10.3$ years (range, 31-63 years) for mothers and fathers, respectively.

One of the boys was an adopted child, one had a father who was dead, and the remaining parents were alive. The education level of the mothers was very low (Table 1). The socioeconomic level was classified depending on the national minimum income (NMI). Low income was defined by equal or less than NMI and middle was twice or third times of the NMI. The socioeconomic levels of the subjects were mostly low $(n=11)$ and middle $(n=3)$.

\section{Comorbidity}

All members of the study group had at least one comorbidity. SUD $(n=8)$ was the most common comorbidity. All SUD cases involved nicotine; in addition, balyvolatile use $(n=1)$, cannabinoid use $(n=1)$, and alcohol use $(n=3)$ were noted.

$\operatorname{ADHD}(n=6)$, major depression $(n=2)$, enurezis nocturna $(n=2)$, and disruptive mood dysregulation $(n=1)$ were the other comorbid disorders. Prior suicide attempts $(n=5)$ and self mutilative $(n=8)$ behaviors were also observed (Table 2). Mental capacity of the cases were classified as normal $(n=8)$ and borderline-normal $(n=6)$ IQ levels consisted with the clinical assessments.

\section{Prognosis}

One of the participants, 14-year-old girl with CD and disruptive mood dysregulation, was lost to follow-up. Although she had been on LAR treatment for two months, her parents had reported minimal improvements, and she ran away from home and got lost. No medication-related reasons for her loss to follow-up were reported. Scores of the remaining participants $(n=13)$ were measured. CGI-S scores of $\mathrm{CD}$ at baseline and treatment end-point ranged from 4 to 7 and 1 to 4 , respectively. We observed a significant difference in CGI-S scores between baseline and end-point assessments $(Z=-3.198 ; p<0.001)$. Seven subjects $(53.8 \%)$ showed much improvement (i.e., a score of 1$)$, three subjects (23.1\%) showed very much improve-

Table 1. Sociodemographic characteristics of the study group

\begin{tabular}{ll}
\multicolumn{1}{c}{ Characteristic } & Number (\%) \\
\hline $\begin{array}{l}\text { Gender of the patients } \\
\text { Female }\end{array}$ & $5(35.7)$ \\
Male & $9(64.3)$ \\
Household & \\
Single-parent & $7(50.0)$ \\
Two-parent & $7(50.0)$ \\
Academic level of the patients & \\
Primary school & $2(14.3)$ \\
Secondary school & $4(28.6)$ \\
High school-dropped & $4(28.6)$ \\
High school & $4(28.6)$ \\
Academic level of the mothers & \\
No education & $4(28.6)$ \\
Primary school & $7(50.0)$ \\
Secondary school & $2(14.3)$ \\
High school/university level & $1(7.1)$ \\
Academic level of the fathers & \\
No education & $0(0)$ \\
Primary school & $8(57.1)$ \\
Secondary school & $4(28.6)$ \\
High school/university level & $2(14.3)$ \\
\hline
\end{tabular}




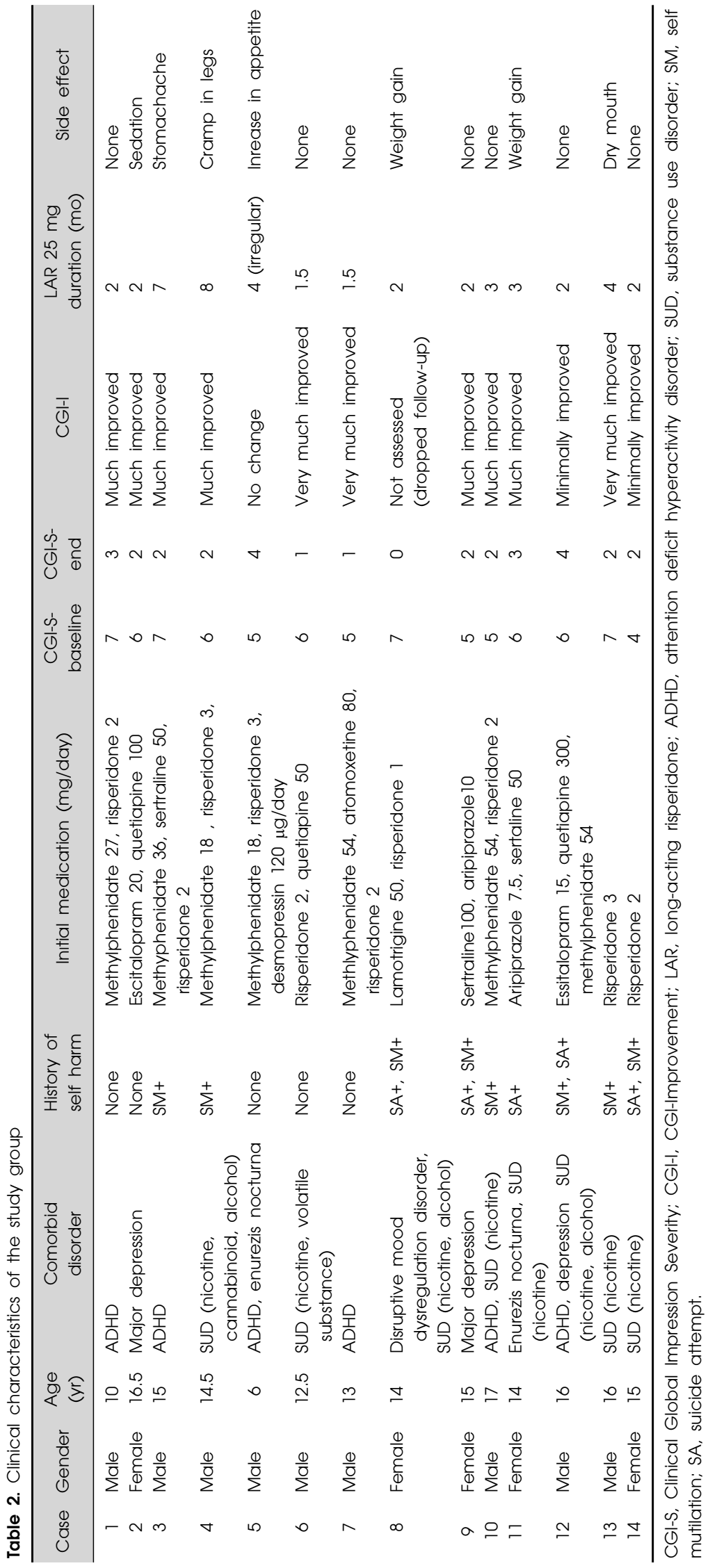




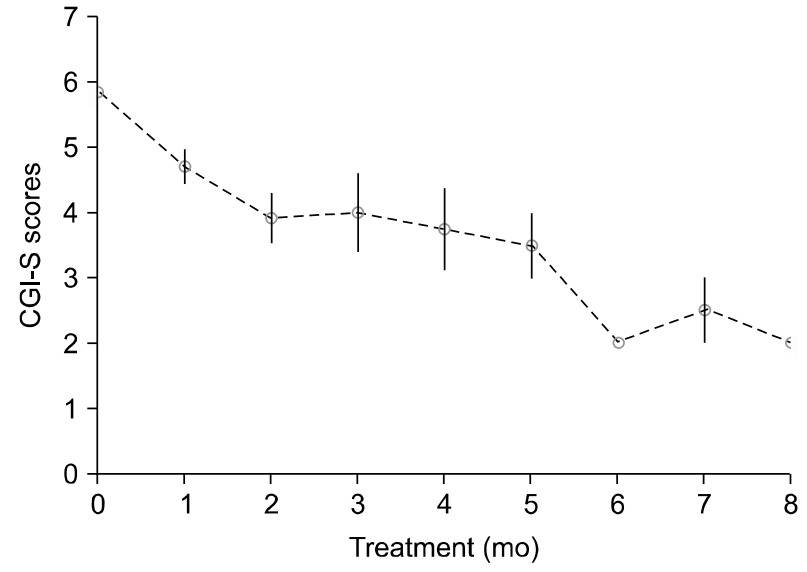

Fig. 1. Clinical Global Impressions--Severity (CGI-S) scores for conduct disorder during treatment.

ment, two showed (15.4\%) mild improvement, and one (7.7\%) subject showed no change in $\mathrm{CD}$ symptoms on the CGI-I scale (Table 2). We obtained CGI-S and CGI-I scores during follow up visits in every month (Figs. 1,2). We observed improvements in CD symptoms starting from the fourth week of LAR use. Mean duration of the treatment was nearly 3.1 months (range, 1.5-8 months). The initial, mean, maintenance and final dose of LAR were $25 \mathrm{mg}$ for two weeks.

The patient with no change was the youngest participant in the study, a 6-year-old boy with CD, ADHD, and enurezis nocturna. His mother was 28 years old and illiterate, his father was 31 years old and had a primary school educational level. These parents had three offsprings and unfortunately both parents were unable to cope with their misbehaving child. The boy was referred to our clinic because of serious rule-breaking and dangerous behaviors towards his peers in school. Family motivation and supervision was insufficient to bring him into our clinic for injections. His compliance to LAR was $50 \%$, where the other patients had obeyed all the scheduled injections (\%100). He only had four injections (instead of the recommended eight) during a four month follow-up period, because his parents were also nonadherent to the depot form. Meanwhile, his parents did not let him go to school. Therefore he was sent to social services for proper care and rehabilitation.

\section{Adverse Effects}

Documented common antipsychotic side effects were asked to the parents and patients. No serious side effects were observed or reported. Weight gain $(n=2)$, sedation $(n=1)$, stomachache $(n=1)$, increase in appetite but no

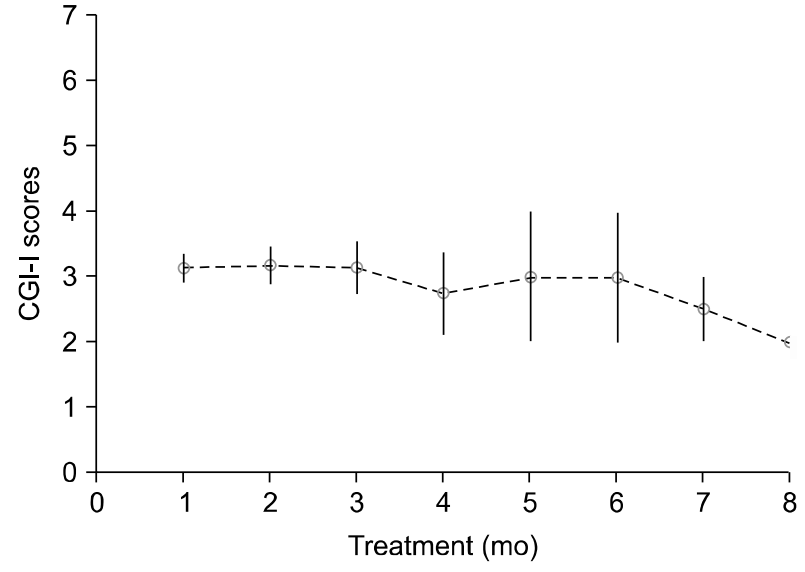

Fig. 2. Clinical Global Impressions- Improvement (CGI-I) scores for conduct disorder during treatment.

weight gain $(n=1)$, muscle cramp in legs $(n=1)$, and dry mouth $(n=1)$ were reported. All of the side effects except weight gain were transient. Weight gain was observed in girls; the 14-year-old girl who dropped out after two months and the second 14-year-old girl who had been on LAR for three months, put on weight that was greater than expected, per national growth norms for children. Painful leg cramps were experienced by one patient and this side effect was considered to be an EPS symptom at first and lasted for a month. In fact, EPS examination was normal in this case, so it was not classified as an EPS symptom later on.

\section{DISCUSSION}

$\mathrm{CD}$ is a disruptive behavior characterized by aggression, oppositionality, noncompliance, and negative emotionality, it may persist throughout the life course, and it is a predictor for antisocial and criminal behaviors in adulthood. Therefore, effective treatment of CD is a crucial mental health concern. ${ }^{9,47)}$ In fact, treatment adherence is a major risk factor for poor outcome. Having a single mother, earlier maternal age at time of birth, and lower socioeconomic status are known risks for the defiant child and disruptive behaviors that lead to increased nonadherence. $^{48,49)}$ Our findings are consistent with these reports. In our study, half of the children were living with a single mother and they primarily came from low socioeconomic status households. The mothers in our study group tended to have low education levels, this is consistent with the findings of the TOSCA study in which the offsprings of mothers with lower education responded better to augmented therapies than to usual care. ${ }^{50)}$ Unfortunately, one of our cases whose mother was very young 
and with no education was nonadherent for LAR use.

LAR use is preferred in patients who refuse oral medications, but there is limited data about its offlabel use in CD. Only one case report by Tutkunkardaş and $\mathrm{Abali}^{35)}$ has been reported in the literature thus far, and they found that LAR is useful in maintaining treatment support in CD. Our study likewise showed that LAR use was effective and well tolerated, as the majority of participants showed very much and much improvement in CD symptoms. One patient showed no response; this might be the result of irregular injections (i.e., a total of four injections instead of the eight that were planned). Other studies on LAR have shown the efficacy and safety of LAR in a variety of conditions such as schizophrenia and bipolar disorder in which patient insight tends to be poor and leads a treatment resistance. $^{36,46)}$

We found that LAR use is effective in increasing adherence and motivation for treatment, even in shorter treatment durations. In some case, six weeks (i.e., three injections) of treatment was sufficient to see improvements. This is consisted with the findings of previous studies. ${ }^{34)}$ The mean duration of the treatment was 3.1 months, which is relatively shorter than other LAR studies in youth. ${ }^{36)}$ It should be noted that those studies included diagnoses of schizophrenia and bipolar disorder. We could not use oral forms of the risperidone together with its depot form. This might explain the fact that we began to observe symptom improvements after the fourth week of injections. Fu-I et $a l .{ }^{34)}$ observed improvements beginning from the third week of treatment, which is consistent with the fact that the Tmax of LAR is 21 days. ${ }^{34,51)}$ The duration between treatment initiation and symptom improvement would have been shorter if we had used LAR and oral risperidone in combination. Short treatment duration for LAR was also our choice, because we did not want to use the offlabel LAR for a greater period of than necessary.

Some of the benefits of long-acting drug forms can be also advantageous for our study sample in terms of treatment adherence. The use of LAR provides regular contacts between the patient and the clinician, in these visits affective stability and impulsive suicidality may be closely monitored and stable plasma levels of the drug leads to reduced risk of deliberate overdose ${ }^{51)}$ Close monitoring is extremely important for our study group, because the majority of our participants had a history of self mutilative behaviors and suicide attempts (all of which were due to drug overdose). Due to poor parental supervision and lack of cooperation with the medical staff, it was very hard to follow-up with such risky adolescents, which was the ini- tial impetus for initiating depot formulation.

Peak plasma levels and slow absorption rate of the LAR are lower than conventional oral forms. The LAR has a lack of first pass metabolism, providing better dose and blood level of the drug, minimize antipsychotic withdrawal symptoms and potential drug-drug interactions. Common side effects of the LAR include; dose-related and time-dependent EPS effects, weight gain, sedation, and hyperprolactinemia. ${ }^{51)}$ In this study we observed mild adverse effects. This might be resulted from short duration and low mean dosage $(25 \mathrm{mg})$ use of the LAR in our group. Side effects observed in our study that were potentially related to the LAR included: weight gain, sedation, stomachache, dry mouth, and muscle cramp. No pain in injection site was reported. We did not observe EPS, in contrast to previous studies reporting fewer EPS side effects with LAR. Muscle cramp was initially considered to be a type of EPS, but the symptom disappeared without intervention and might have been produced by transient causes such as exhaustion or electrolyte imbalance. Weight gain is the significant adverse effect associated with most types of AA. Weight gain has important morbidities and can even lead to mortality, therefore clinicians must weigh this issue when they are dealing with growing individuals. ${ }^{52}$

To the best of our knowledge, this study is the first study of LAR use in CD. We conducted a DSM criteria based semi-structured interview and used standard scales for outcomes measures. A blinded researcher who did not know the patients evaluated the results to decrease rater bias. However, there are some limitations that should be taken into account. First of all, this study utilized a retrospective design. Recall bias might lower the reliability of the study. On the other hand, the retrospective design did not affect the clinicians' decisions on children's improvement of symptoms of $\mathrm{CD}$ because a blinded rater filled the CGI forms every visit. The patients and their parents were the ones who reported the presence of adverse effects, side effects might have been subject to recall bias. We would rather use objective rating scales for side effects as well. Second, the small sample size limits the generalizability of our findings. Third, the participants were primarily from low socioeconomic families, were part of single-parent households, and had parents (especially mothers) with low education levels. Other behavioral scales for disruptive behaviors were not administered. This is also a limitation of our study. Additional factors that may have contributed to adherence, such as parental psychopathology, school performance, bullying, trauma, other adverse 
life events were not assessed. We observed mild side effects; perhaps the short duration (mean duration is 3.1 months), stable use and the lowest LAR dose (25 mg) might favor adverse effects. Finally almost all our patients $(n=13)$ are adolescents which limits the generalizability of the LAR use for the prepubescent age groups. Despite these limitations, our study is important for providing data on LAR use in $\mathrm{CD}$, which is lacking in the literature.

In conclusion, Our findings are consistent with those of previous studies investigating the use of LAR as an alternative or supportive treatment in youth with various psychiatric disorders and for whom there are concerns about treatment compliance. ${ }^{35,40,51)}$ We showed that even short-term application of a depot formulation is useful for maintaining medication compliance, which is consistent with previous reports. ${ }^{34,35,40)}$ The current study shows that LAR injection is useful for adolescents with CD who cannot be medicated with oral preparations and/or who are nonadherent to initial treatment. Childhood use of depot risperidone has not been sufficiently studied thus far, yet it is a drug of choice for improving adherence and deserves careful consideration. Therefore, given the lack of official approval of LAR for CD, randomized double-blind control studies with prospective design and larger sample size are needed so as to further assess the efficacy and safety of this treatment regimen.

$\mathrm{CD}$ is a major risk factor for antisocial adult behavior, therefore early intervention is extremely important. We showed that LAR can be a supportive medication in CD. It may be the drug of choice for youth who fail to respond to prior pharmacotherapy trials or who experience adherence problems due to poor parental supervision, oppositional behaviors, and expressing challenging behaviors to himself and his surroundings. The short-term low dose use of LAR for CD to maintain a treatment adherence is effective and safe.

\section{REFERENCES}

1. American Psychiatric Association. Diagnostic and statistical manual of mental disorders: DSM-5. 5th ed. Washington, D.C.:American Psychiatric Association;2013.

2. Costello EJ, Mustillo S, Erkanli A, Keeler G, Angold A. Prevalence and development of psychiatric disorders in childhood and adolescence. Arch Gen Psychiatry 2003;60: 837-844.

3. Rey J, Walter G, Soutullo C. Oppositional defiant and conduct disorders. In: Martin A, Volkmar FR, Lewis M, editors. Lewis's child and adolescent psychiatry: A comprehensive textbook. 4th ed. Philadelphia:Lippincott Williams \& Wilkins;2007. p.454-467.

4. Steiner H. Practice parameters for the assessment and treatment of children and adolescents with conduct disorder. J Am Acad Child Adolesc Psychiatry 1997;36(10 Suppl):
122S-139S.

5. Sawyer MG, Arney FM, Baghurst PA, Clark JJ, Graetz BW, Kosky RJ, et al. The mental health of young people in Australia: key findings from the child and adolescent component of the national survey of mental health and well-being. Aust N Z J Psychiatry 2001;35:806-814.

6. Ercan ES, Basay BK, Basay O, Durak S, Ozbaran B. Risperidone in the treatment of conduct disorder in preschool children without intellectual disability. Child Adolesc Psychiatry Ment Health 2011;5:10.

7. Fergusson DM, Horwood LJ, Ridder EM. Show me the child at seven: the consequences of conduct problems in childhood for psychosocial functioning in adulthood. $J$ Child Psychol Psychiatry 2005;46:837-849.

8. Moffitt T. Life-course-persistent versus adolescence-limited antisocial behavior. In: Cicchetti D, Cohen DJ, editors. Developmental psychopathology. 2nd ed. Hoboken, NJ: John Wiley \& Sons;2006. p.570-598.

9. Odgers CL, Moffitt TE, Broadbent JM, Dickson N, Hancox RJ, Harrington $\mathrm{H}$, et al. Female and male antisocial trajectories: from childhood origins to adult outcomes. Dev Psychopathol 2008;20:673-716.

10. Erskine HE, Ferrari AJ, Polanczyk GV, Moffitt TE, Murray $\mathrm{CJ}$, Vos $\mathrm{T}$, et al. The global burden of conduct disorder and attention-deficit/hyperactivity disorder in 2010. J Child Psychol Psychiatry 2014;55:328-336.

11. Kazdin AE. Parent management training: evidence, outcomes, and issues. J Am Acad Child Adolesc Psychiatry 1997;36:1349-1356.

12. Kazdin AE. Parent management training: treatment for oppositional, aggressive, and antisocial behavior in children and adolescents. New York:Oxford University Press;2005.

13. Kim BN. The clinical use of risperidone in child \& adolescent psychiatry. Clin Psyhcopharmacol Neurosci 2003; 1(Suppl):178-187.

14. Gurnani T, Ivanov I, Newcorn JH. Pharmacotherapy of aggression in child and adolescent psychiatric disorders. $J$ Child Adolesc Psychopharmacol 2016;26:65-73.

15. Findling RL, Kauffman R, Sallee FR, Salazar DE, Sahasrabudhe V, Kollia G, et al. An open-label study of aripiprazole: pharmacokinetics, tolerability, and effectiveness in children and adolescents with conduct disorder. J Child Adolesc Psychopharmacol 2009;19:431-439.

16. Masi G, Milone A, Canepa G, Millepiedi S, Mucci M, Muratori F. Olanzapine treatment in adolescents with severe conduct disorder. Eur Psychiatry 2006;21:51-57.

17. Connor DF, McLaughlin TJ, Jeffers-Terry M. Randomized controlled pilot study of quetiapine in the treatment of adolescent conduct disorder. J Child Adolesc Psychopharmacol 2008; 18:140-156.

18. Crystal S, Olfson M, Huang C, Pincus H, Gerhard T. Broadened use of atypical antipsychotics: safety, effectiveness, and policy challenges. Health Aff (Millwood) 2009; 28:w770-w781.

19. Turgay A, Binder C, Snyder R, Fisman S. Long-term safety and efficacy of risperidone for the treatment of disruptive behavior disorders in children with subaverage IQs. Pediatrics 2002;110:e34.

20. Findling RL, Aman MG, Eerdekens M, Derivan A, Lyons B; Risperidone Disruptive Behavior Study Group. Longterm, open-label study of risperidone in children with severe disruptive behaviors and below-average IQ. Am J Psychiatry 2004;161:677-684.

21. Ipser J, Stein DJ. Systematic review of pharmacotherapy of disruptive behavior disorders in children and adolescents. 
Psychopharmacology (Berl) 2007;191:127-140.

22. Pliszka SR, Crismon ML, Hughes CW, Corners CK, Emslie GJ, Jensen PS, et al; ; Texas Consensus Conference Panel on Pharmacotherapy of Childhood Attention Deficit Hyperactivity Disorder. The Texas Children's Medication Algorithm Project: revision of the algorithm for pharmacotherapy of attention-deficit/hyperactivity disorder. J Am Acad Child Adolesc Psychiatry 2006;45:642-657.

23. Aman MG, Bukstein OG, Gadow KD, Arnold LE, Molina $\mathrm{BS}, \mathrm{McNamara} \mathrm{NK}$, et al. What does risperidone add to parent training and stimulant for severe aggression in child attention-deficit/hyperactivity disorder? J Am Acad Child Adolesc Psychiatry 2014;53:47-60.e1.

24. Gadow KD, Brown NV, Arnold LE, Buchan-Page KA, Bukstein OG, Butter E, et al. Severely aggressive children receiving stimulant medication versus stimulant and risperidone: 12-month follow-up of the TOSCA trial. J Am Acad Child Adolesc Psychiatry 2016;55:469-478.

25. US Food and Drug Administration. Prescribing information [Internet]. US FDA; 2015. Available from: https://www. accessdata.fda.gov/drugsatfda_docs/label/2009/020272s056, 020588s044,021346s033,021444 s03lbl.pdf.

26. Gerlach M, Mehler-Wex C, Schimmelmann BG. Antipsychotics. In: Gerlach M, Warnke A, Greenhill LL, editors. Psychiatric drugs in children and adolescents: Basic pharmacology and practical applications. Wien:SpringerVerlag;2014. p.157-218.

27. Pringsheim T, Hirsch L, Gardner D, Gorman DA. The pharmacological management of oppositional behaviour, conduct problems, and aggression in children and adolescents with attention-deficit hyperactivity disorder, oppositional defiant disorder, and conduct disorder: a systematic review and meta-analysis. Part 2: antipsychotics and traditional mood stabilizers. Can J Psychiatry 2015;60:52-61.

28. Breen R, Thornhill JT. Noncompliance with medication for psychiatric disorders. CNS Drugs 1998;9:457-471.

29. Adler LD, Nierenberg AA. Review of medication adherence in children and adults with ADHD. Postgrad Med 2010;122:184-191.

30. Thiruchelvam D, Charach A, Schachar RJ. Moderators and mediators of long-term adherence to stimulant treatment in children with ADHD. J Am Acad Child Adolesc Psychiatry 2001;40:922-928.

31. Chacko A, Newcorn JH, Feirsen N, Uderman JZ. Improving medication adherence in chronic pediatric health conditions: a focus on ADHD in youth. Curr Pharm Des 2010;16:2416-2423.

32. Nosé M, Barbui C, Gray R, Tansella M. Clinical interventions for treatment non-adherence in psychosis: meta-analysis. Br J Psychiatry 2003;183:197-206.

33. Vieta E, Nieto E, Autet A, Rosa AR, Goikolea JM, Cruz $\mathrm{N}$, et al. A long-term prospective study on the outcome of bipolar patients treated with long-acting injectable risperidone. World J Biol Psychiatry 2008;9:219-224.

34. Fu-I L, Boarati MA, Stravogiannis A, Wang YP. Use of risperidone long-acting injection to support treatment adherence and mood stabilization in pediatric bipolar patients: a case series. J Clin Psychiatry 2009;70:604-606.

35. Tutkunkardaş MD, Abali O. Long acting risperidone in an adolescent with conduct disorder: a case report. Psychopharmacol Bull 2011;44:69-72.

36. Boarati MA, Wang YP, Ferreira-Maia AP, Cavalcanti AR, Fu-I L. Six-month open-label follow-up of risperidone long-acting injection use in pediatric bipolar disorder. Prim Care Companion CNS Disord 2013;15:PCC.12m01368.

37. Karakoc Demirkaya S, Zoroglu S. Long acting injectable risperidone use in an 11-year-old bipolar child. Arch Neuropsychiatr 2016. doi: 10.5152/npa.2015.10150.

38. Ruan L, Hu S, Huang M, Hu J, Cai W. Efficacy and safety of long-acting risperidone on early onset schizophrenia in adolescent patients. African $J$ Pharmacy Pharmacol 2010;4:184-192.

39. Chou YH, Chu PC, Wu SW, Lee JC, Lee YH, Sun IW, et al. A systemic review and experts' consensus for long-acting injectable antipsychotics in bipolar disorder. Clin Psychopharmacol Neurosci 2015;13:121-128.

40. Umehara H, Iga J, Ohmori T. Successful treatment of anorexia nervosa in a 10-year-old boy with risperidone long-acting injection. Clin Psychopharmacol Neurosci 2014; 12:65-66.

41. Pierre JM. Extrapyramidal symptoms with atypical antipsychotics: incidence, prevention and management. Drug Saf 2005;28:191-208.

42. Kaufman J, Birmaher B, Brent D, Rao U, Flynn C, Moreci $\mathrm{P}$, et al. Schedule for Affective Disorders and Schizophrenia for School-Age Children-Present and Lifetime version (K-SADS-PL): initial reliability and validity data. $J \mathrm{Am}$ Acad Child Adolesc Psychiatry 1997;36:980-988.

43. Gökler B, Ünal F, Pehlivantürk B, Kültür EÇ, Akdemir D, Taner Y. Reliability and Validity of Schedule for Affective Disorders and Schizophrenia for School Age ChildrenPresent and Lifetime version-Turkish version (K-SADSPL-T). Turk J Child Adolesc Ment Health 2004;11:109-116.

44. American Psychiatric Association. Diagnostic criteria from DSM-IV-TR. Washington, D.C.:American Psychiatric Association;2000.

45. Busner J, Targum SD. The clinical global impressions scale: applying a research tool in clinical practice. Psychiatry (Edgmont) 2007;4:28-37.

46. Emsley R, Oosthuizen P, Koen L, Niehaus DJ, Medori R, Rabinowitz J. Oral versus injectable antipsychotic treatment in early psychosis: post hoc comparison of two studies. Clin Ther 2008;30:2378-2386.

47. Nevels RM, Dehon EE, Alexander K, Gontkovsky ST. Psychopharmacology of aggression in children and adolescents with primary neuropsychiatric disorders: a review of current and potentially promising treatment options. Exp Clin Psychopharmacol 2010;18:184-201.

48. D'Onofrio BM, Goodnight JA, Van Hulle CA, Rodgers JL, Rathouz PJ, Waldman ID, et al. A quasi-experimental analysis of the association between family income and offspring conduct problems. J Abnorm Child Psychol 2009;37:415-429.

49. Murray J, Irving B, Farrington DP, Colman I, Bloxsom CA. Very early predictors of conduct problems and crime: results from a national cohort study. J Child Psychol Psychiatry 2010;51:1198-1207.

50. Farmer CA, Brown NV, Gadow KD, Arnold LE, Kolko DG, Findling RL, et al. Comorbid symptomatology moderates response to risperidone, stimulant, and parent training in children with severe aggression, disruptive behavior disorder, and attention-deficit/hyperactivity disorder. I Child Adolesc Psychopharmacol 2015;25:213-224.

51. Sacchetti E, Grunze H, Leucht S, Vita A. Long-acting injection antipsychotic medications in the management of schizophrenia. Evidence-based Psychiatr Care 2015;1:27-36.

52. Arango C, Giráldez M, Merchán-Naranjo J, Baeza I, Castro-Fornieles J, Alda JA, et al. Second-generation antipsychotic use in children and adolescents: a six-month prospective cohort study in drug-naïve patients. J Am Acad Child Adolesc Psychiatry 2014;53:1179-1190,1190.e1-4. 